Portland State University

PDXScholar

Dissertations and Theses

Dissertations and Theses

Summer 1-2-2013

\title{
Self-Disclosure and Self-Efficacy in Online Dating
}

Andrew Christopher España

Portland State University

Follow this and additional works at: https://pdxscholar.library.pdx.edu/open_access_etds

Part of the Gender, Race, Sexuality, and Ethnicity in Communication Commons, Interpersonal and Small Group Communication Commons, and the Social Media Commons

Let us know how access to this document benefits you.

\section{Recommended Citation}

España, Andrew Christopher, "Self-Disclosure and Self-Efficacy in Online Dating" (2013). Dissertations and Theses. Paper 889.

https://doi.org/10.15760/etd.889

This Thesis is brought to you for free and open access. It has been accepted for inclusion in Dissertations and Theses by an authorized administrator of PDXScholar. Please contact us if we can make this document more accessible: pdxscholar@pdx.edu. 
Self-Disclosure and Self-Efficacy in Online Dating

by

Andrew Christopher España

A thesis submitted in partial fulfillment of the requirements for the degree of

\author{
Master of Science \\ in \\ Communication
}

Thesis Committee:

Leslie Rill, Chair

Susan Poulsen

Priya Kapoor

Portland State University

2012 


\title{
SELF-DISCLOSURE AND SELF-EFFICACY IN ONLINE DATING
}

\begin{abstract}
This study explores online dating by studying the relationship between selfdisclosure and self-efficacy in an online dating environment. This research study examines the way self-disclosure, self-efficacy, self-esteem, and gender interrelate in an online dating environment. This study includes, but is not limited to, discussion of the type of correlation between self-efficacy and self-esteem, the relationship between selfdisclosure and self-efficacy, and the differences between men's and women's selfdisclosure in an online dating environment.
\end{abstract}

From conducting this study, the researcher was able to determine that there is a statistically significant relationship between gender and how it relates to self-disclosure and self-efficacy. With the results from the study, the understanding of how different variables relate to online dating and romantic relationships has been taken one step further as it helps fill the gap in the literature. 


\section{SELF-DISCLOSURE AND SELF-EFFICACY IN ONLINE DATING}

\section{Table of Contents}

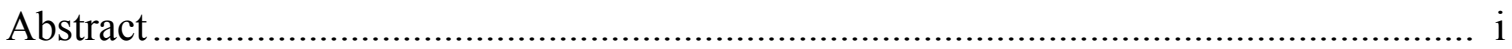

Chapter 1: Introduction ...................................................................................... 1

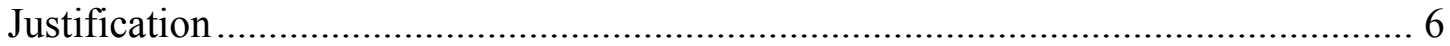

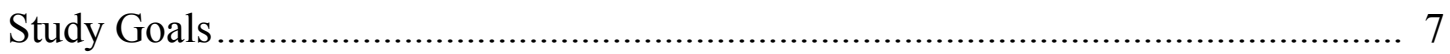

Chapter 2: Literature Review .................................................................................... 9

Computer-Mediated Communication .................................................................... 9

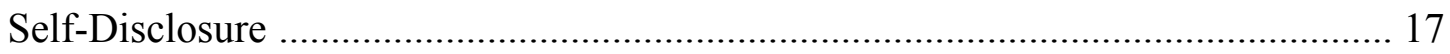

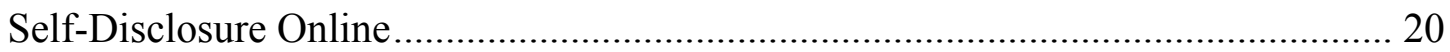

Gender Differences in Self-Disclosure ………………...................................... 28

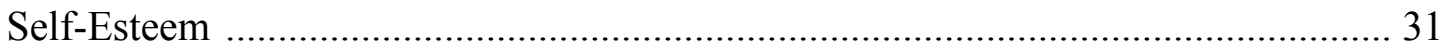

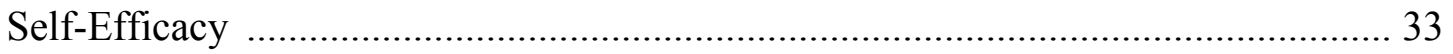

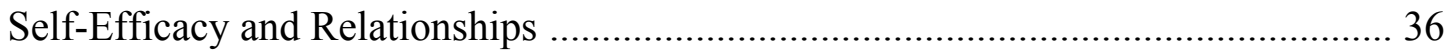

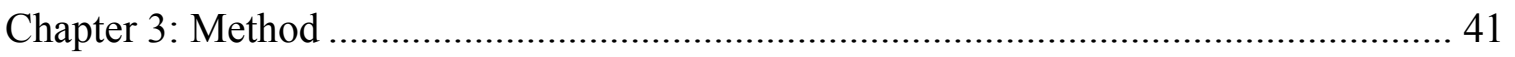

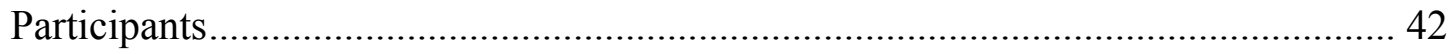

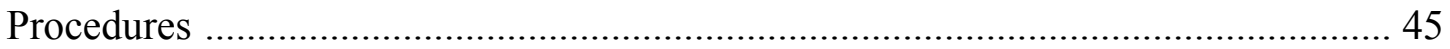

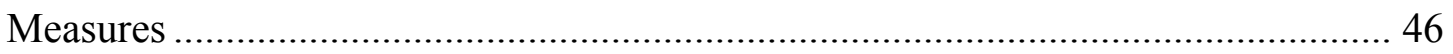

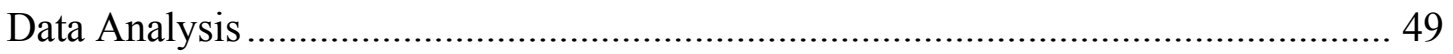

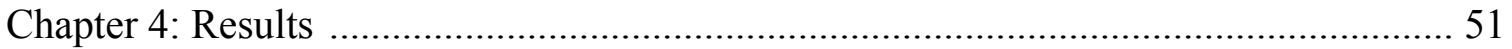

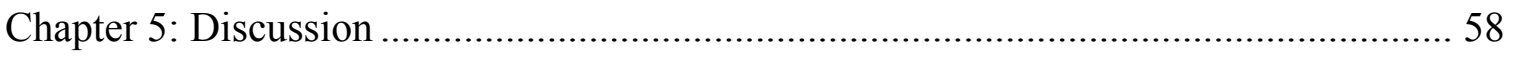

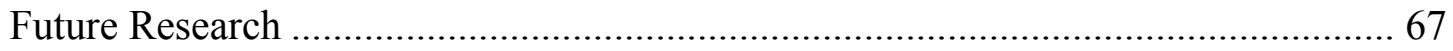




\section{SELF-DISCLOSURE AND SELF-EFFICACY IN ONLINE DATING}

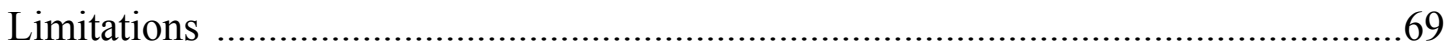

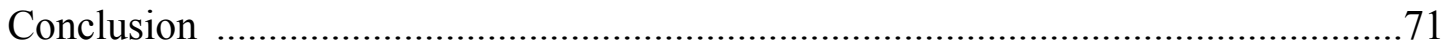

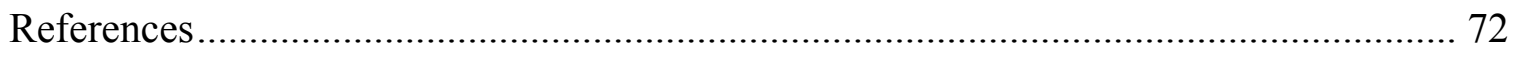

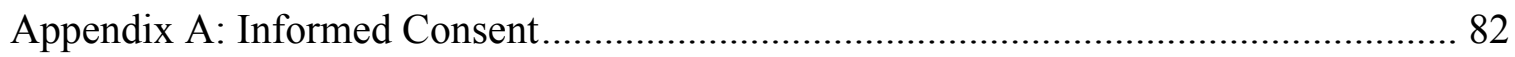

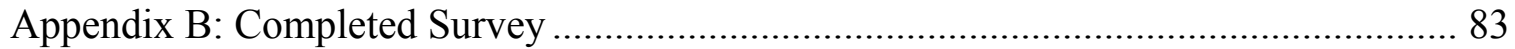




\section{SELF-DISCLOSURE AND SELF-EFFICACY IN ONLINE DATING}

\section{Chapter 1: Introduction}

Romantic courting behaviors have evolved over the generations in a variety of ways, including the structure, style and type of communication used. From a time when poetic letters were sent by horsemen to their loved ones, communication has evolved into an era where people can poke, wink, nudge, and send icebreakers digitally.

In Colonial America, marriage had less to do with romance than it does today; instead, men focused on finding women who could bear children and help live the rugged frontier life ("Finding True Love," 2005). By the mid-1800s there was a shortage of women, which spurred men to place ads in local newspapers in order to solicit for a wife. An example from an Arkansas newspaper reads, "Any gal that got a bed, calico dress, coffee pot and skillet, knows how to cut out britches and can make a hunting shirt, knows how to take care of children can have my services till death do us part" ("Finding True Love," 2005). Flash forward to the $20^{\text {th }}$ century, and it is possible to see that courting has evolved into a much more romantic style of dating. Dating has gone through several evolutions, from the feminist freedom period in the 1960s with birth control, to dating TV 


\section{SELF-DISCLOSURE AND SELF-EFFICACY IN ONLINE DATING}

shows, to the present day and the invention of modern-day computers that have Internet capabilities that foster dating Web sites such as match.com and eHarmony.com. This brief snapshot of dating or courting does not just encapsulate dating, but it also demonstrates the roles men and women have had in society and how they have evolved over time as well. Women are not just courted to bear children but instead are treated as equals throughout society. With the equality of men and women, there is a lot more even participation of who is pursuing whom in the dating world, even in online dating.

People are frequently connecting online, not just as friends or work associates; people have turned to the Internet in hopes of romantically connecting to another person. Initially, there was a stigma associated with online dating, but our society has been shedding this stigma (Wong, 2010). People who participate in online dating are no longer labeled "socially stunted nerds" (Wong, 2010, para. 2).

Despite the possible risk of finding that someone looks different than they appear online, U.S. society is embracing this new social activity with exponential interest. According to match.com (2012), one in five people participate in online dating today. This may seem like a surprising statistic, but when one thinks about how fast-paced and 


\section{SELF-DISCLOSURE AND SELF-EFFICACY IN ONLINE DATING}

interconnected peoples lives have become, this statistic is easier to comprehend. Online dating has increased in popularity since it became available in 1995 as more people have gained access to computers and have connected through online dating Web sites. This has allowed individuals to easily intertwine their everyday lives with an active search for a romantic partner. Furthermore, eHarmony.com (2012), one of the leading online dating Web sites, claims that it is responsible for nearly $5 \%$ of the marriages in the U.S. This not only demonstrates that people are turning to online dating as a means of courting, but that online dating can work: It could lead to marriage and companionship.

Rosenfeld and Thomas (2011) explained in their study that since 1995, the percentage of Americans meeting their partners online has risen drastically. In turn, the percentage of couples meeting through the traditional means has declined. At the annual meeting of the American Sociological Association, Rosenfeld and Thomas explained that "With the meteoric rise of the Internet as a way couples meet in the past few years, and the concomitant recent decline in the central role of friends, it is possible that in the next several years the Internet could eclipse friends as the most influential way Americans meet their romantic partners, displacing friends out of the top position for the first time 


\section{SELF-DISCLOSURE AND SELF-EFFICACY IN ONLINE DATING}

since the early 1940s" (para. 4). As one can see, romantic dating is going through a shift and transformation as more people and activities become available online. Their research and statement supports the need for the present study as societal norms are possibly entering an era that has yet to be studied, with the Internet serving as popular route to foster romantic relationships.

With this need for a study present, it was possible to identify a gap in the literature and aim to contribute to the current literature. The present study analyzes selfdisclosure and self-efficacy in online dating and identifies the relationship they share. As discussed in the literature review, self-disclosure is considered a foundation of all romantic relationships. In essence, self-disclosure is the process in which an individual communicates personal information to another individual. Understanding this variable and its role in online dating environments opens up new possibilities of how this variable needs to be studied. One aspect in need of being studied is how self-disclosure relates to other variables, such as self-efficacy. Self-disclosure has been widely studied in a variety of ways, but there is a gap in the literature: Self-disclosure has not yet been studied the way the present study researches this variable. 


\section{SELF-DISCLOSURE AND SELF-EFFICACY IN ONLINE DATING}

Self-efficacy is understood as a variable that represents an individual's opinion on his or her ability to perform a task; as such, there is the possibility of a relationship between the variables being discovered. This will be further discussed in the literature review, but the link between self-disclosure and self-efficacy can be best conceptualized when one gains a full understanding of self-esteem. Self-esteem will play a role as a bridging variable to help show the connection between self-disclosure and self-efficacy. With an understanding of the variables, one could understand how an individual who has low-self efficacy with face-to-face dating could possibly have high rates of selfdisclosure in online dating environments.

Computer-mediated communication has progressed since computers were

invented, even within the last 10 years. Social networks are some of the most-visited Web sites in the world. According to Alexxa.com (2012), a site that monitors Internet traffic, Facebook.com is the second most visited Web site in the United States and rest of the world. Through computer-mediated communication, individuals are given a chance to meet other individuals with an ease and frequency that was not possible for previous generations. With this new technology, social behavior norms and expectations have 


\section{SELF-DISCLOSURE AND SELF-EFFICACY IN ONLINE DATING}

shifted. This shift has generated an ample amount of research that helps provide an understanding of the new phenomenon.

One area in need of being studied is the way in which certain variables relate to one another in this online dating environment. This present study seeks to gain an understanding of how self-disclosure and self-efficacy are related in an online dating environment. To help provide this understanding and meet the present study's goal, selfesteem will be studied and used to help bridge the relationship between self-disclosure and self-efficacy. Through the literature review, it is possible to see how these variables are connected, but the present study will detect the actual existence of this relationship between variables. This study not only fills the gap in the current literature of interpersonal communication with what we already know about these variables and online dating but also adds knowledge to this growing phenomenon.

\section{Justification}

As further outlined in the literature review, Sprecher and Hendrick (2004)

explained that self-disclosure is in need of further study. The increasing number of people participating in online dating is generating new avenues to be studied. By conducting this 


\section{SELF-DISCLOSURE AND SELF-EFFICACY IN ONLINE DATING}

study, a greater knowledge of self-disclosure, self-esteem, and self-efficacy can be achieved through identifying a possible, yet-undiscovered relationship between two previously well-studied variables. With this knowledge, the understanding of the rising phenomenon of romantic relationships forming online will be one step further ahead.

This general area of study is not unique, but the context and way in which the variables are studied is. Currently, there is not any reported research—or any found in a review of the literature - that analyzes self-disclosure and self-efficacy together in an online dating environment. With a gap in the present literature and other academic scholars identifying a need for this study, this research is justified in its potential to contribute to the academic literature.

\section{Study Goals}

Based on the justification above, this study attempts to contribute to the knowledge base already established regarding self-disclosure and self-efficacy. As mentioned earlier, the literature regarding how these two variables relate to one another has been non-existent. With this in mind, the researcher intends to identify the possible relationship between these two variables. 


\section{SELF-DISCLOSURE AND SELF-EFFICACY IN ONLINE DATING}

Furthermore, this study aims to identify how these two variables interrelate and the type of relationship they may share. Through the data analysis, the researcher will be able to determine whether the two variables are correlated and, if so, how strongly correlated they are. The researcher will also provide a discussion with further insight into how self-disclosure and self-efficacy are related in an online dating environment. The following chapter consists of a literature review that provides insight into the current literature surrounding the study. The discussion in Chapter 2 includes computer-mediated communication, self-disclosure, self-esteem, and self-efficacy, and it helps craft the argument for why this study needed to be conducted. The literature review is followed by a discussion of the quantitative method in Chapter 3. In Chapter 4, the researcher provides the results to the research questions and support for the hypotheses. Following Chapter 4, the researcher provides a discussion in Chapter 5 regarding how the translated results contribute to the communication and online dating literature. 


\section{SELF-DISCLOSURE AND SELF-EFFICACY IN ONLINE DATING}

\section{Chapter 2: Literature Review}

This literature review encompasses the following topics to set the foundation of why the present study was needed: computer-mediated communication, self-disclosure, self-disclosure online, gender differences in self-disclosure, self-esteem, self-efficacy, and self-efficacy and relationships. The literature reviewed below helps provide an understanding of how variables within the present study are understood today.

\section{Computer-Mediated Communication}

Thurlow, Lengel, and Tomic (2005) define computer-mediated communication as "any human communication achieved through, or with help of, computer technology" (p. 15). Computer-mediated communication has a very broad spectrum of examples, among them, conversations within online chat rooms, e-mail communication, blog postings, and online dating.

One could posit that, through the use of computer technology intertwined with communication, basic styles, structures, and expectations people have of communication have shifted. For example, people expect correspondence to take place much faster via email than via a hand-written letter. The available technology in computer-mediated 


\section{SELF-DISCLOSURE AND SELF-EFFICACY IN ONLINE DATING}

communication allows for new styles and platforms for communication to take place, such as online dating.

Computer-mediated communication allows for relationships to generate and also functions as a platform through which relationships are facilitated. Two of the types of relationships that can be facilitated by computer-mediated communication are simple friendships and romantic relationships. There have been many viewpoints expressed about romantic relationships generated online and the impact this has on one's life, but conflicting views continue to generate.

Examples of the various views regarding online romantic relationships were exhibited through the research of Cocking and Matthews (2001) and of Briggle (2008).

Cocking and Matthews explained that the Internet poses a variety of challenges that prohibit close relationships exclusively online. Briggle argued that offline relationships can be constrictive and insincere, "distorting important indicators and dynamics in the formation of close friends" (p. 71). Briggle supported computer-mediated friendships by arguing that distance promotes the courage to be candid and encourages honesty in how individuals speak to each other. Briggle also explained that oral exchanges in the offline 


\section{SELF-DISCLOSURE AND SELF-EFFICACY IN ONLINE DATING}

world are often too hasty or shallow to promote deep bonds. Briggle discussed the positive effects computer-mediated communication has by stating that "the deliberateness

of written correspondence acts as a weight to submerge friendships to greater depths and as a brake to enhance attentiveness to and precision about one's own and one's friend's character" (p. 71). Briggle contended that computer-mediated contexts, including the Internet, can promote close friendships.

One may initially assume that computer-mediated communication lacks verbal communication cues to achieve depth; however, Lo (2008) explained that although emoticons present themselves as verbal cues, they perform nonverbal functions. Lo's study demonstrated that computer-mediated communication is able to achieve a level of depth in regards to emotion, attitude, and attention expression that all relationships need in order to grow. The results from Lo's study suggested that emoticons perform nonverbal communication functions that parallel traditional face-to-face nonverbal communication cues.

Anderson and Emmers-Sommer (2006) acknowledged additional face-to-face communication qualities that are represented in computer-mediated communication 


\section{SELF-DISCLOSURE AND SELF-EFFICACY IN ONLINE DATING}

settings, such as online dating. Results from their study indicated that intimacy, trust, and communication satisfaction were significant predictors of online romantic relationship satisfaction. Anderson and Emmers-Sommer did acknowledge that intimacy, trust, and communication satisfaction are also strong face-to-face relational components. As Anderson and Emmers-Sommer stated, "communication is a central component of establishing and developing relationships, and in online relationships simple, everyday interaction allows partners to maintain their relationships" (p. 166). From reviewing the literature revolving around computer-mediated communication, one can see that a major category of the relationships generated online contain romance. Romantic relationships online have evolved from simplistic e-mails to a fully-developed online community of online daters.

One major type of computer-mediated communication is online dating (i.e. communication and romantic relationship formation initiated online). In online dating, as in some other computer-mediated communication forms, a vast majority of the get-toknow-you phase takes place instantly when individuals read one another's profiles. All the information that users put into their profiles derives from the personal experiences 


\section{SELF-DISCLOSURE AND SELF-EFFICACY IN ONLINE DATING}

each individual has as they answer the profile-related questions. With all this information available for other online daters to read, online daters' self-disclosure is expedited by skipping the introductory stage of self-disclosure and allowing for a deeper connection at the beginning of a relationship compared to a face-to-face encounter where the profiletype information would be disclosed more slowly over time.

To help understand key differences between face-to-face communication and computer-mediated communication among romantic partners, several differences are outlined. These differences help provide clarity about the changing communication style that has been identified as well as provide insight into why online dating is increasing in popularity.

First, there are less auditory and visual cues in online communication compared to face-to-face communication (Walther \& Parks, 2002), including less emphasis on physical attractiveness in online communication (Cooper \& Sportolari, 1997). Walther and Parks (2002) explained that with the structure of communication (sender, receiver, channel, feedback) available in computer-mediated communication, the communication style is able to shift from traditional face-to-face communication to an online format that 


\section{SELF-DISCLOSURE AND SELF-EFFICACY IN ONLINE DATING}

enables hyper-personal communication. By definition, if hyper generally means over and above, one can see that the communication between participants in online dating environments or other computer-mediated communication platforms can be very enticing and could lead to romantic relationship development. Messages that are hyperpersonalized may provide a tailored message that may have a greater impact on the receiver.

Second, the frequency and depth with which people communicate to one another differs in computer-mediated communication vs. offline communication. Through computer-mediated communication, corresponding messages and emoticons can be sent instantaneously to continuously stay connected to another individual. With this said, the depth to which online daters communicate could be more in-depth compared to offline communication. For example, communicators online can be secluded at their private computers, where they may feel more comfortable, in their controlled environment, disclosing information to each other.

Third, Levine (2000) articulated that flirting online is not the same as flirting in face-to-face scenarios. In Levine's research of the virtual medium, flirting was based on 


\section{SELF-DISCLOSURE AND SELF-EFFICACY IN ONLINE DATING}

"words, charm, and seduction" (p. 565) and not on physical attraction. Levine highlighted

five components of attraction and then connected these components to online

relationships. Although these components dealt with attraction, they highlight some of

the key characteristics of romantic relationships that are facilitated online.

The first component of attraction is proximity and frequency of contact, which, as

Levine described, is vastly different between computer-mediated communication and

face-to-face communication. Individuals can be across the globe communicating through

e-mail or instant messenger versus typical face-to-face meetings where they have to

communicate at those encounters. The second component of attraction online is self-

presentation. Online participants have the ability to greatly control self-presentation

compared to face-to-face encounters. The participant has the ability to manipulate images

and present only the information of which they want the other participants to be aware.

Third, Levine explained that there is ample research that has identified that people who

share relationships together appear similar in multiple ways, "demographics being the

most obvious (age, family background, religion, education, etc.), similarity has also been

found in personalities and interests between two people who are attracted to each other" 


\section{SELF-DISCLOSURE AND SELF-EFFICACY IN ONLINE DATING}

(p. 570). The fourth component of attraction is reciprocity and self-disclosure. This will be outlined in more detail in a later section, but closeness emerges from sharing information with another individual. The fifth and last component of online attraction is expectations and idealization. As Levine explained, everyone has an ideal lover in his or her mind. With computer-mediated communication, there is often ambiguity in the messages sent and received: Messages can be misinterpreted, or they could contain unintended meanings or even intentional ambiguity. This ambiguity allows one's mind to idealize what the person on the other computer screen might be like. Additionally, with individuals being able to spend time crafting their message to another individual, idealization is possible.

Bargh and McKenna (2004) concluded that the Internet has qualities that are unique and perhaps transformational as a communicative channel. These qualities include relative anonymity and the ability to easily connect with other individuals who possibly share the same interests, hobbies, values, and beliefs. As Bargh and McKenna articulated, "research has found that the relative anonymity aspect encourages self-expression, and the relative absence of physical and nonverbal interaction cues (e.g., attractiveness) 


\section{SELF-DISCLOSURE AND SELF-EFFICACY IN ONLINE DATING}

facilitates the formation of relationships on other, deeper bases such as shared values and beliefs" (p. 586).

Now that the understanding of relationships being generated in computermediated environments has been established, it is time to gain the understanding of how people disclose information to one another in online and offline environments and use different methods to connect with another individual.

\section{Self-Disclosure}

Self-disclosure has been defined in various ways, as this variable is constantly being researched and analyzed. Self-disclosure was defined by one of its original researchers, Sidney Jourard (1964), as "letting another person know what you think, feel, or want" (p. 24). Over the years, there has been discourse regarding the scope of the definition and whether it should include nonverbal communication acts. For example, Greene, Derlega, and Mathews (2006) suggested that all verbal and nonverbal behaviors reveal something about the self. In turn, this results in any communicative act being defined as self-disclosure.

With these definitions in mind, the researcher developed a conceptual definition 


\section{SELF-DISCLOSURE AND SELF-EFFICACY IN ONLINE DATING}

for the purpose of this study. Self-disclosure will be conceptually defined in online and offline settings as intimate and/or personal information disclosed by an individual concerning their past, present, or future that is not readily available to anyone. A prime example of self-disclosure is when two people are getting to know each other and the information communicated between them contains facts or stories that are not readily available to others. In an online environment, this information is not found through quickly reading someone's profile; engaging in a conversation in any medium is where this information becomes exposed.

The purpose of self-disclosure in traditional, face-to-face communication is to exchange pieces of intimate information about the self in order to further understand and get to know another individual in the hope of formulating a relationship. For this study, this relationship will be a romantic online relationship. In a typical offline dating situation, the level and depth of self-disclosure between the individuals could take place in a day, a week, a month, or even longer, depending on the individual situation; however, in an online dating environment, self-disclosure could provide a slightly different experience.

Typically, for the online dating process, an individual registers him- or herself 


\section{SELF-DISCLOSURE AND SELF-EFFICACY IN ONLINE DATING}

online with a dating Web site. Once registered, the individual submits photographs and enters any pieces of information she or he wants the online dating community to know about her- or himself. Oftentimes, this information includes interests, hobbies, age, race, and views. Once all this information is submitted, his or her online dating profile is complete. Other individuals can now view the individual's profile and look at the pictures and information he or she elected to disclose online. If another individual is interested, she or he can often send a message (e-mail), an emoticon, a wink, a poke, a hug, etc. to express to the person that she or he is interested in getting to know him or her. The key characteristic that is unique to online dating compared to face-to-face communication is that. through the online dating profiles, the individuals may already know a great deal of information about each other prior to meeting, so the communication is expedited and often begins with a conversation with more depth.

To understand when self-disclosure takes place and how self-disclosure works in romantic relationships, Altman and Taylor (1973) created a theory that does just that: the social penetration theory. In short, the social penetration theory posits that the more time we spend with others, the more likely we are to disclose more personal or intimate 


\section{SELF-DISCLOSURE AND SELF-EFFICACY IN ONLINE DATING}

information about our lives. The social penetration theory is also known as the onion theory because the theory is based on the notion that as you peel each layer of disclosure and have deeper conversations, you are getting closer to the core of an individual. As relationships develop, the individuals will share more aspects of themselves with more breadth and depth. For example, every individual has breadth (the various topics incorporated in your life). As you converse and share information regarding these topics, the depth at which you share information increases with every piece of information exchanged. Thus, the concept peeling the onion layers.

Social penetration theory explains how self-disclosure takes place between individuals. Because the linkage between self-disclosure and romantic relationships serves as a key variable in this study, it is beneficial to understand this theory and how it relates to online dating to help provide background knowledge of this variable.

\section{Self-Disclosure Online}

With interpersonal communication as one of the dominant uses of the Internet, according to Alexxa.com (2011), it is critical to recognize the previously-conducted research that examines self-disclosure in computer-mediated environments. Self- 


\section{SELF-DISCLOSURE AND SELF-EFFICACY IN ONLINE DATING}

disclosure, in an online environment, focuses on the exchange of pieces of intimate information about the self in order to further understand and get to know another individual in the hope of formulating a relationship. Some differences between online and offline environments are the rate at which the "onion layers" are peeled off and how individuals self-disclose information.

In the online dating environment, individuals often have profiles that contain personal information that would otherwise be revealed during the self-disclosure process during the initial dates in an offline context. By having information from an individual's profile readily accessible to anyone, the process of self-disclosure is expedited.

If an individual begins to participate in online dating and starts to communicate with someone else, the conversation typically bypasses the surface-level conversation that is often generated during face-to-face communication because the information is already available in the individual's profile. The social penetration theory is applicable to self-disclosure online: The outer layer of the onion is bypassed and the individuals begin to discuss topics at a deeper level. This theory provides a visual metaphor for understanding self-disclosure and serves as a great example when discussing self- 


\section{SELF-DISCLOSURE AND SELF-EFFICACY IN ONLINE DATING}

disclosure. Another key feature in online dating is the method of self-disclosure.

Typically, self-disclosure in online dating is more direct and is initiated from the

beginning through conversations on a deeper level.

Duck and McMahan (2009) discussed the relationship filtering model (Duck,

$1988,1999)$ as a way of understanding how individuals form an impression of another

person, which in turn leads to friendship or romantic relations. By understanding how this

filtering model works, one can conceptualize the social penetration theory with more ease

and see how it's applicable. Duck and McMahan (2009) explained that the order in which

one pays attention to characteristics is essentially the order in which one encounters

them: physical appearance, behavior/nonverbal cues, roles, and attitude/personality. The

relationship filtering model suggests that as people get filtered out, the ones remaining

become either friends or lovers.

One can see how Duck's relationship filtering model suggests an applicable

method for understanding how self-disclosure occurs and develops into a friendship or

romantic relationship, and how this process may occur in combination with the social

penetration theory. 


\section{SELF-DISCLOSURE AND SELF-EFFICACY IN ONLINE DATING}

Self-disclosure usually occurs in face-to-face encounters over an extended period

of time: the get-to-know-you time. However, in online dating this process can be

expedited because the technology enables the transfer of information to occur much more rapidly due to similarities in online profiles. Gibbs, Lai, and Ellison (2009) supported this claim when they stated that "the design of online dating sites and their emergent norms for behavior encourage early disclosure of a great deal of intimate information which is typically not explicitly shared in initial face-to-face encounters" (p. 4). Due to the information that is available to everyone to read prior to conversing, it is possible to see that the design of online dating sites and profiles on social networking sites encourage rapid disclosure.

To demonstrate the speed of partner identification and conversation initiation, Frost, Chance, Norton, and Ariely (2008) explained that with technology, online daters exhibit similar behavior as online shoppers. Specifically, online daters are able to spend seven times as many hours screening profiles and e-mailing potential partners than in actual face-to-face encounters. This study helps articulate the advantage online daters have in terms of screening potential partners in order to find the one(s) they want. Having 


\section{SELF-DISCLOSURE AND SELF-EFFICACY IN ONLINE DATING}

this much extra time allocated to narrowing down dating options could possibly be connected to the expedited disclosure rates and the disclosure depths that are often associated with online dating. For example, by the time an individual communicates with a potential partner, the screening process utilized will bypass all the initial small talk that a typical face-to-face setting may possess, such as where someone is from, age, race, sex, hobbies, etc., and the daters could transition into a deeper conversation more quickly.

Tidwell and Walther (2002) explained that individuals in an online environment have a greater level of self-disclosure through their probes and intermediate questioning and disclosure than face-to-face participants. The direct form of communication, by the chatting participants online, demonstrates the quicker rate at which uncertainty reduction takes place in an online environment compared to offline environments. Tidwell and Walther stated, "it seems likely that the increased intimacy of these micro-level behaviors may lead to perceptions of extraordinarily affectionate relations, or hyper $=$ personal states, as seen in recent studies among long-term [computer-mediated communication] partnerships" (p. 339).

Tidwell and Walther (2002) concluded in their study that individuals disclosing 


\section{SELF-DISCLOSURE AND SELF-EFFICACY IN ONLINE DATING}

information online and adapting to the limitations of computer-mediated communication "compensate for the limitations of [computer-mediated communication] by hyperpersonalizing their interactions, presumably leading to accelerated gains in attributional confidence over the course of their brief conversations" (p. 342). The researchers noted that individuals who perceived limitations through computer-mediated communication compensated for it by engaging in more personalized conversations. Tidwell and Walther explained that the information exchanged online contains more intimate questions and disclosures compared to the average face-to-face interaction.

With some individuals having more successful intimate conversations online, many of these individuals began their conversations with strangers through online dating sites or other social networks. Because they don't know one another, the online dating participants have to face pressures to reveal personal information. The pressures the online dating participant encounters is in regard to conforming with social norms in generating and maintaining a romantic relationship (Gibbs., et al, 2009). Mesch and Beker (2010) supported this and argueed that the interaction of users in online environments creates new norms of self-disclosure and social interactions. These new 


\section{SELF-DISCLOSURE AND SELF-EFFICACY IN ONLINE DATING}

norms of self-disclosure are individualized to ensure that the communication between parties is as comfortable and effective as they would like to make it. Lawson and Leck (2006) also agreed that on the Internet there is pressure to disclose much information in a short time to establish trust and kinship quickly. This can be due to the design of the social networks and online dating Web sites with the number of questions one has to answer and information that one is required to disclose. As outlined in other literature in this review, computer-mediated communication often facilitates a more intimate conversation setting, which encourages users to disclose information. This points to the very essence of how self-disclosure can differ from face-to-face encounters: online daters experience an expedited self-disclosure process compared to a prolonged, face-to-face dating scenario.

To further explain differences, Merkle and Richardson (2000) provided research about self-disclosure by briefly comparing and contrasting communication through computer-mediated relationships and traditional face-to-face relationships. Merkle and Richardson argued that communication in a computer-mediated environment allows the participants to have less anxiety about disapproval when sharing information with other 


\section{SELF-DISCLOSURE AND SELF-EFFICACY IN ONLINE DATING}

participants because individuals remain anonymous and have a faster and greater breadth

of self-disclosure. Wysocki $(1996,1998)$ supported this notion by providing research that indicated that people participating in online communication often build relationships at a faster pace. Wysocki contended that this is due to people in face-to-face communication being less psychologically comfortable due to the possibilities of being disapproved of by the other.

Rosen, Cheever, Cummings, and Felt (2008) examined the process of online dating, the similarities and differences between online and offline dating, and the emotions and self-disclosure on first impressions via e-mail with a potential partner. The results indicated that in traditional-style dating, personal information, personality types, and education levels are the most important predictors of self -disclosure. By contrast, online daters focus on communication style and physical attractiveness.

Sprecher and Hendrick (2004) conducted a longitudinal study offline that supported their argument that self-disclosure has been shown to positively relate to love, romantic relationship satisfaction, and relationship ability. These findings allude to the idea that self-disclosure has a pivotal role in the formation and maintenance of romantic 


\section{SELF-DISCLOSURE AND SELF-EFFICACY IN ONLINE DATING}

relationships. Their results revealed the strong relationship that self-disclosure has with intimate relationships. Gibbs, Ellison, and Heino (2006) supported this notion in their online study by explaining that the more self-disclosure takes place, the more intimate the relationship becomes, and thus a higher level of relational satisfaction can be achieved.

This research outlines the possible link self-disclosure has with romantic relationship development in both online and offline environments and also explains the differences depending on the environment. Another variable that impacts self-disclosure is gender. The following articles articulate the impact gender has on self-disclosure.

\section{Gender Differences in Self-Disclosure}

Research has demonstrated that there are differences in how men and women self-

disclose information to one another (citations here). When it comes to self-disclosure about a sexual or intimate topic, Yuan (2002) demonstrated that in a cyber or online environment women are more repressed or constrained about their sexuality. Chiou (2006) found that men self-disclose about sexual topics more liberally than women. Both of the studies indicated that gender power structures in an offline context can be replicated in an online environment. Yuan (2002) provided a possible explanation by 


\section{SELF-DISCLOSURE AND SELF-EFFICACY IN ONLINE DATING}

finding, through research, that Taiwanese women felt that cybersex is unsafe and unreal in regard to the use of sex chat rooms.

To further outline the differences, Griffin and Sparks (1990) acknowledged that, in general, women disclose more about their fears and weaknesses than men do.

Although these variations in disclosure exist in face-to-face communication, Griffin and Sparks acknowledged that in online environments, due to anonymity, the variations in disclosure shift as new online platforms emerge.

In addition, Boneva, Kraut, and Frohlich (2001) conducted a study that sought to reveal gender differences when using email for personal relationships. The data resulting from this study replicated preexisting gender differences; that is, in comparison to men, women found e-mail contact between friends and family to be more gratifying, and women are more likely than men to maintain close relationships through the utilization of e-mail. Women are also more likely to use e-mail to keep in touch with friends and family who live far away.

Future researchers can use the knowledge generated by the previously-conducted research on self-disclosure discussed above to discover new links among new variables. 


\section{SELF-DISCLOSURE AND SELF-EFFICACY IN ONLINE DATING}

The self-disclosure research included in this literature review discusses studies conducted in important issues surrounding online dating, including gender differences in selfdisclosure, offline vs. online self-disclosure frequency, the process of self-disclosure, maintenance, and other relationship factors that provide the foundation this for research study. With that said, the researcher posits Hypothesis 1:

Hypothesis 1: Self-disclosure differs by gender in online romantic relationships.

By reviewing the self-disclosure literature, one is able to see the depth with which self-disclosure has been researched and the pivotal role self-disclosure has in relationships.

People have self-esteem at various levels throughout their lives. In regards to romantic relationships, individuals with high self-esteem could have less anxiety about the possibility of being rejected by, or of being incompatible with, the people with whom they initiate a conversation. The following articles describe what self-esteem is and demonstrates the link between self-esteem and relationship formation and development. 


\section{SELF-DISCLOSURE AND SELF-EFFICACY IN ONLINE DATING}

\section{Self-Esteem}

Before identifying literature that connects self-esteem to self-disclosure, it is

critical to gain an understanding of what self-esteem actually is. Mruk (2006) stated that

there have been over 23,000 articles, chapters, and books discussing self-esteem. For the purpose of this study, self-esteem can be best understood as how we value ourselves and what we perceive our value to be to others. With positive self-esteem, individuals often exhibit the strength and willpower to change their lives and learn from their mistakes without the fear of rejection. Typical behaviors of individuals with high self-esteem are confidence, optimism, self-direction, and the ability to trust other people. Conversely, if an individual has low self-esteem, they often feel unworthy, incapable, and incompetent. Typical behaviors for individuals with low self-esteem include a negative view on life, blaming others, mistrusting, dependence, and a fear of being ridiculed.

To understand how self-esteem is linked to romantic relationships, scholars have conducted numerous studies (citation here). Sciangula and Morry (2009) conducted a study that explored the relationships among self-esteem, perceived regard, and satisfaction with dating relationships. Their analyses acknowledged that self-esteem and 


\section{SELF-DISCLOSURE AND SELF-EFFICACY IN ONLINE DATING}

perceived regard for moderate relationship-relevant traits (i.e., caring, loving) are predictors of satisfaction. Further connecting self-esteem to romantic relationships, the study demonstrated that higher self-esteem and greater idealization predict higher relationship satisfaction among dating couples. However, individuals who exhibit low self-esteem about themselves or relationships lead to less relationship satisfaction and more negative relationship experiences.

MacGregor and Holmes (2011) had several unique findings in their study regarding self-esteem and its connection to self-disclosure. They found that there is ample evidence indicating that the behavior of people with low self-esteem can lead to problems in close relationships. They also found that in written and verbal communication in a romantic relationship, people were less positive in their disclosures when they believed that that the recipient possessed low self-esteem. This study demonstrated the positively correlated link that self-esteem and self-disclosure share in romantic relationships. Also, in an international study, Arslan, Hamarta, and Uslu (2010), indicated that self-esteem and self-disclosure were positively correlated.

Thus, it can be hypothesized: 


\section{SELF-DISCLOSURE AND SELF-EFFICACY IN ONLINE DATING}

Hypothesis 2: Self-esteem is positively correlated to self-disclosure within romantic relationships online.

\section{Self-Efficacy}

As Bandura (1994) argued, self-efficacy has been defined as "people's beliefs about their capabilities to produce designated levels of performance that exercise influence over events that affect their lives. Self-efficacy beliefs determine how people feel, think, motivate themselves and behave" (para. 1). Bandura further asserted that a strong sense of self-efficacy enhances an individual's human accomplishment and personal well-being. Zulkosky (2009) discussed self-efficacy not concerning an individual's skill level at completing tasks but rather with judgments of what the individual can do with those specific skills.

There has been research conducted that sought to examine the role of self-efficacy in work environments, in educational environments, and in general settings (citations here). Pajares (n.d.) noted that various researchers have expressed the need to explore self-efficacy and its generality. Bandura (1997) cautioned researchers against utilizing self-efficacy as a "psychological grail of generality" (p. 24), but did acknowledge the 


\section{SELF-DISCLOSURE AND SELF-EFFICACY IN ONLINE DATING}

critical understanding it could provide to communication research. One example of how self-efficacy has been examined in an academic setting is a study conducted by Junge and Dretzke (1995). Their findings demonstrated that there could be gender differences in self-efficacy depending on the environment in which it is studied. Their study regarding mathematical self-efficacy identified strong gender differences. Furthermore, they identified a gender aligning itself strongly with stereotypical activities. For example,

findings strongly suggest that there are gender differences associated with self-efficacy. Self-efficacy is normally studied in academic or workplace settings because, in general, these settings contain a lot of tasks needing to be completed. If self-efficacy is going to be applied to an online dating setting, the task at hand would be finding a partner.

Self-esteem can be easily misunderstood and interpreted as self-efficacy. Before continuing, it is critical to understand the difference between self-efficacy and selfesteem, as there seems to be less research conducted regarding self-efficacy. In essence, self-esteem is a general feeling about one's self-worth, and self-efficacy is one's confidence in one's ability to achieve a certain outcome. Self-esteem is similar to selfefficacy; in general, the difference is that self-efficacy is regarding the execution of a 


\section{SELF-DISCLOSURE AND SELF-EFFICACY IN ONLINE DATING}

specific task.

As previously stated, self-esteem and self-efficacy are different, but these terms are often used interchangeably and have great similarity. Pajares and Schunk (2001) explained the difference:

The conceptual and empirical differences between self-efficacy and self-concept are not always clear to researchers or in research studies. Some authors use the terms synonymously; others describe self-concept as a generalized form of selfefficacy; still others argue that self-efficacy is simply a part, or a kind, of selfconcept. But the difference between self-efficacy and self-esteem beliefs is not cosmetic. Self-efficacy is a judgment of the confidence that one has in one's abilities; self-concept is a description of one's own perceived self accompanied by an evaluative judgment of self-worth. (p. ?)

For example, an individual may have high self-esteem when it comes to athletics but possess a low sense of self-efficacy when performing on the balance beam in gymnastics. Now that it has been established what self-efficacy is and how it differs from self-esteem, the researcher can posit a research question that aims to identify the 


\section{SELF-DISCLOSURE AND SELF-EFFICACY IN ONLINE DATING}

relationship between self-efficacy and self-esteem.

RQ1: Is there a positive correlation between an individual's level of self-efficacy and his or her level of self-esteem?

\section{Self-Efficacy and Relationships}

In romantic relationships, there are hardships that every individual endures at

some point. In Burt, Lewis, Beverly and Patel's (2010) study, participants (doctoral

students) noted a lack of social outlets outside their academic environment, which

contributed to the low sense of self-efficacy and relationship formation. Participants of

that study also noted that educational attainment limited their availability to participate in

social gatherings, and some participants even noted having limited knowledge of social

gatherings.

Through the hardships higher education places on individuals, the opportunities

for romance one wishes one could experience are sparse. The resulting low self-efficacy

could possibly change to higher self-efficacy if an individual seeks opportunities they

could have more success with, such as online dating. While not directly addressing online

dating, the present study demonstrates that self-efficacy could be related to online dating 


\section{SELF-DISCLOSURE AND SELF-EFFICACY IN ONLINE DATING}

despite the sparse amount of research already conducted. This study goes further than demonstrating the link between self-efficacy and online dating; it also suggests that selfefficacy could be linked to other variables with which self-efficacy is not commonly paired in the research, such as self-disclosure. With that said, there has been little or no research conducted that has sought to examine the relationship between self-efficacy and self-disclosure.

In regards to a variable discussed earlier - self-disclosure - there could be possible links to self-efficacy. If an individual thinks she or he is not good at finding or building a relationship, her or his ability or willingness to self-disclose information could be linked. In essence, individuals who exhibit high levels of self-efficacy are more likely to approach difficult tasks as opportunities to be mastered rather than hurdles to avoid. Individuals who exhibit high self-efficacy levels set challenging goals to complete; in contrast, individuals who doubt their abilities to complete difficult tasks may shy away and view them as possible personal threats, making those goals unattainable.

Individuals with low self-efficacy levels have low aspirations and a weak commitment to completing any goals they set (Bandura, 1994). To draw a connection 


\section{SELF-DISCLOSURE AND SELF-EFFICACY IN ONLINE DATING}

between self-efficacy and self-disclosure, it could be said that if an individual faces a

difficult task (i.e. speaking to a potential partner in a face-to-face situation), he or she may turn to alternative means of accomplishing the objective, such as online dating. Thus it can be posited that different levels of self-efficacy are connected to self-disclosure in online dating.

Bandura (year) asserted that if individuals exhibit weak self-efficacy, the most effective way of generating stronger self-efficacy is through mastering experiences and challenges at hand. In short, success experiences increase one's efficacy levels; however, if a failure takes place, the failure could undermine it. One needs to keep in mind that self-efficacy differs from the colloquial term "confidence" because self-efficacy is linked to a specific task one completes, whereas confidence is generally referred to as one's general self-demeanor. Similarly, Bandura (1997) explained that confidence refers to strengths of belief, but does not necessarily specify what the certainty is about. Selfefficacy includes the capability level as well as the strength of the belief.

Through this research, one is able to build a foundational understanding of a sparsely-researched topic. With the interpretation from the various findings, research 


\section{SELF-DISCLOSURE AND SELF-EFFICACY IN ONLINE DATING}

direction and opportunities may rest with the link between self-efficacy and self-

disclosure. In the articles reviewed pertaining to self-efficacy, multiple scholars have demonstrated the versatility and global presence self-efficacy has in any given situation.

With the understanding that self-efficacy is one's perception of how well one can

complete a certain task with one's skills, it can be suggested that if an individual has low self-efficacy when it comes to participating in traditional face-to-face dating situations,

the individual will pursue online dating as an alternative route to achieving success in dating. The task at hand in an online dating scenario is engaging in a romantic relationship with another individual.

There is a need for further study of the link between self-efficacy and relationship formation, and more specifically between self-efficacy and self-disclosure. There has yet to be a study conducted that identifies the relationship self-disclosure and self-efficacy may share. For example, if an individual wants to participate in online dating, the question can be posed: does he or she possess low or high self-efficacy with selfdisclosure? By gaining this knowledge, a greater understanding of self-disclosure can be established, as this will identify a possible new link between variables in an online dating 


\section{SELF-DISCLOSURE AND SELF-EFFICACY IN ONLINE DATING}

environment.

It is possible to see through the literature that self-disclosure is connected to computer-mediated communication and romantic relationship formation/development.

Furthermore, the literature demonstrates the relationship self-disclosure and self-esteem share. With self-esteem and self-efficacy being studied and understood in a very similar way, the link between these two variables directs the researcher to a possible undiscovered relationship between self-disclosure and self-efficacy.

Identifying this relationship between the two variables and gaining this understanding will allow for greater knowledge of how relationships develop in this increasing phenomenon — online dating — and also answer three additional research questions:

RQ2a: Is there a relationship between self-efficacy and the degree of selfdisclosure in online dating relationships?

RQ2b: Are gender differences present in the relationship between self-disclosure and self-efficacy in an online dating environment? 


\section{SELF-DISCLOSURE AND SELF-EFFICACY IN ONLINE DATING}

\section{Chapter 3: Method}

In order to conduct this study and make a contribution to the existing literature,

the researcher utilized a method that was able to illuminate the potential relationship between self-disclosure and self-efficacy in an online dating environment. In order to accomplish this, the researcher determined that best results would be generated through a quantitative study. Through this methodology, the researcher was able to draw a generalizable conclusion to further our knowledge about self-disclosure, self-efficacy, and self-esteem.

The rationale for selecting quantitative over qualitative came down to the need to measure the variables rather than describe them. The quantitative study allowed the researcher to measure the strength of relationships between variables. Babbie (2007) explained that through quantitative studies the researcher is able to make his or her claim more explicit. Additionally, "it also can make it easier to aggregate, compare, and summarize data" (p. 23). For this study, this aligns perfectly with the types of research questions in need of being studied. This study focuses on identifying a possible relationship between self-disclosure and self-efficacy. Through a statistical analysis 


\section{SELF-DISCLOSURE AND SELF-EFFICACY IN ONLINE DATING}

conducted in SPSS, this study sought to identify and measure relationships between variables to fill the gap in the literature. This study will not only provide a deeper understanding of how self-disclosure and self-efficacy are related but also an understanding of the impact these variables have in online dating and additional insight into the role self-esteem plays in relationship to the other two variables.

For the sample that this study researched, the researcher elected to utilize the survey design method. The study utilized pre-existing scales and survey questions to accurately research this sample. As Babbie (year) stated, "survey research is probably the best method available to the social researcher who is interested in collecting original data for describing a population too large to observe directly" (p. 244). The following sections outline the specifics for the different components of the methodology.

\section{Participants}

The researcher employed a non-probability volunteer sampling method. This design yielded a sample that consisted of 194 participants $(N=194)$. Of the 194 participants, the age range was $18-65$ years of age $(M=31.51, S D=10.82)$. The sample consisted of 81 women (41.80\%), 112 men (57.70\%), and one participant who did not 


\section{SELF-DISCLOSURE AND SELF-EFFICACY IN ONLINE DATING}

answer this question $(0.50 \%)$. The sample for the study consisted primarily of Caucasian participants $(n=147,75.80 \%)$, followed by Asian/ Pacific Islander participants $(n=18$, 9.30\%), African/American participants $(n=13,6.70 \%)$, Hispanic or Latino/a participants $(n=8,4.10 \%)$, Indian/Native American participants $(n=2,1.00 \%)$, and participants who identified themselves as two or more races $(n=1,0.50 \%)$.

As for education, $89(45.90 \%)$ participants indicated that they had some college experience, $66(34.00 \%)$ had earned their bachelor's degree, nine $(4.60 \%)$ had earned their master's degree, and five (2.60\%) had earned their doctoral degree. Furthermore, the range for the participants' annual household income was most frequently selfreported at $\$ 30,000$ - $\$ 50,000$ by $50(25.80 \%)$ of the participants. Following this, 47 $(24.20 \%)$ of the participants self-reported an annual household income of $\$ 10,000$ $\$ 30,000,36(18.60 \%)$ indicated their annual household income was $\$ 50,000-\$ 75,000,29$ $(14.90 \%)$ indicated their income was \$75,000-\$150,000, $27(13.90 \%)$ indicated they earned less than $\$ 10,000$, and, finally, three $(1.5 \%)$ indicated their earnings were greater than $\$ 150,000$.

When the participants self-reported their answers regarding online dating activity 


\section{SELF-DISCLOSURE AND SELF-EFFICACY IN ONLINE DATING}

and Internet use, 113 participants indicated they have had an online dating relationship, while 80 participants indicated they had not. One participant did not respond. With this information, the researcher conducted an ANOVA test and determined that there is a statistical difference in the variables between individuals who had indicated they

participated in online dating activity versus individuals who had not. For the data analysis on the research questions and hypotheses, the researcher analyzed data from the 113 participants who indicated they had participated in online dating activities.

Of those who had indicated they had participated in online dating, the average amount of time a participant spent being an active member of an online dating Web site was zero to three months $(M=2.93, S D=1.59)$. Additionally, participants indicated that they spent 1.60 days per week $(S D=1.82)$ actively looking online for a romantic partner. The participants also indicated that on average they spent 1.30 hours per day $(S D=2.98)$ participating in online dating activity. For those who had found a relationship online, the range in the longest duration of their online romance was one month to six years $(M=$ $16.87, S D=19.70)$ 


\section{SELF-DISCLOSURE AND SELF-EFFICACY IN ONLINE DATING}

\section{Procedure}

Before beginning the study, a proposal was given to the Institutional Review Board (IRB) to ensure that the human participants' rights and interests were protected. The researcher used Mechanical Turk to help facilitate a randomized sample. The researcher accessed Mechanical Turk and provided the survey to the group of online survey takers (i.e. workers). These participants received monetary compensation for their time and effort, up to $\$ 0.30$ cents for their participation.

Each participant was instructed to take the survey once. Upon entering the survey, participants first encountered an informed consent page (Appendix A), which ensured that all participants were volunteering and had a full understanding of what the study entailed. Anonymity and confidentiality were guaranteed and outlined in the informed consent form.

The researcher utilized pre-existing scales from previously identified research for self-disclosure, self-esteem, and self-efficacy. The survey also included demographic questions, questions regarding frequency of Internet usage, and questions identifying online dating activity. The 47-item questionnaire was tested at taking an average of 5 


\section{SELF-DISCLOSURE AND SELF-EFFICACY IN ONLINE DATING}

minutes and 8 seconds to complete. This information was outlined at the beginning of the survey (see Appendix B for full questionnaire).

The data was downloaded from the Internet site and then uploaded into the SPSS data analysis program to identify the relationship between self-disclosure and selfefficacy in online dating. During the data analysis process, a codebook was generated and retained in order to keep record of variable locations and the meanings of the codes assigned.

\section{Measures}

The questionnaire was comprised of four sections: questions about self-efficacy, questions about self-disclosure, questions about self-esteem, and descriptive questions which included demographic and lifestyle questions pertaining to Internet use and dating. The following four sub-sections outline the measure used for each of the studied variables.

\section{Self-disclosure.}

Participants were asked to self-report responses to survey questions derived from a 16-item General Disclosiveness scale utilized in a previous study (Wheeless, 1978). For 


\section{SELF-DISCLOSURE AND SELF-EFFICACY IN ONLINE DATING}

the present study, the researcher utilized a modified version of the General

Disclosiveness scale (Gibbs, Ellison, \& Heino, 2006). Some modifications to the original

scale were made, including dropping some items from the original scale and revising item wording to suit an online setting. The scale measures patterns of disclosure regarding honesty (truthfulness), amount (quantity and total information disclosed), conscious intent (purposeful disclosure/strategic motivation), and positive valence (information disclosed in a positive or negative nature). As tested in the present study, each subscale's Cronbach's are as follows: honesty $\alpha=.93$, amount $\alpha=.71$, conscious intent $\alpha=.61$, and valence $\alpha=.87$. Respondents rated their level of agreement on a Likert-type scale with each statement ranging from 1 (strongly disagree) to 5 (strongly agree). For example, when faced with the question, "I am always honest in my disclosures to those I meet online," the participant had the option of selecting one of the aforementioned categories to show how strongly he or she agreed with the statement (Appendix B). There were six items on the scale that were reverse-coded and also reverse-coded during the data analysis. 


\section{SELF-DISCLOSURE AND SELF-EFFICACY IN ONLINE DATING}

\section{Self-efficacy.}

Participants were asked to self-report responses to survey questions originating

from the 8-item New General Self-Efficacy scale (Chen, Gully, \& Eden, 2001). The scale measures one's frequency of patterns with self-efficacy $(\alpha=.87)$. Respondents rated their level of agreement with each statement on a 5-point Likert-type scale ranging from 1 (strongly disagree) to 5 (strongly agree). Sample items included, "I will be able to successfully overcome many challenges" and "I will be able to achieve most of the goals that I have set for myself' (see Appendix B for all items). With self-efficacy referring to how well an individual completes a task, the task in an online dating scenario is engaging in a romantic relationship online.

\section{Self-esteem.}

Participants self-reported responses to survey questions originating from the 10item Rosenberg Self-Esteem scale (Rosenberg, 1989; $\alpha=.91$ ). The scale measures selfesteem levels within individuals. Where self-esteem is considered a positive or negative way in which one may view oneself, this scale is able to measure the different levels of self-esteem for each individual. Respondents rated their level of agreement with each 


\section{SELF-DISCLOSURE AND SELF-EFFICACY IN ONLINE DATING}

statement on a 5-point Likert-type scale ranging from 1 (strongly disagree) to 5 (strongly

agree). For example, if the survey stated, "I feel that I have a number of good qualities," the participant chose the response that most accurately demonstrated how strongly he or she agreed with the statement. Items $3,5,8,9$, and 10 on the original scale were reversecoded during the data analysis.

\section{Descriptive demographic data.}

Participants were asked to self-report their responses to several demographic questions while taking the survey. The questions included age, race, sex and miscellaneous Internet dating questions. These survey questions were categorical and open-answer to gain a full understanding of the demographics surrounding the research.

\section{Data Analysis}

Upon completion of the survey, the collected data was exported as an Excel file to eliminate any possible data-entry errors. After the transfer to Excel, the researcher reviewed the data and ensured that the entries were completed properly. Six sets of participant responses were deleted due to the participants not following directions and not 


\section{SELF-DISCLOSURE AND SELF-EFFICACY IN ONLINE DATING}

completely filling out the survey. The Excel document was then uploaded to IBM SPSS and organized. Prior to the data analysis, the necessary scale items were reverse-coded.

To answer the research questions and hypothesis presented in this study, the researcher conducted a correlation test for RQ1, RQ2a, RQ2b, and Hypothesis 2, but an ANOVA was conducted for Hypothesis 1. 


\section{SELF-DISCLOSURE AND SELF-EFFICACY IN ONLINE DATING}

\section{Chapter 4: Results}

RQ1 sought to see if a positive correlation exists between two of the study's variables: self-esteem and self-efficacy. To answer this research question, the researcher had to identify the relationship these two variables share by conducting a correlation test to determine the strength of the relationship and possibly determine if one variable is a predictor of the other.

The test revealed that there is a statistically significant positive correlation between the two variables, $r(111)=.63, p<.01$. According to Cronk (2012), significance levels will be between -1.0 and 1.0. Scores close to 0.0 are of weak significance and scores closer to 1.0 and -1.0 are considered highly significant. In addition, Cronk explained that correlations greater than .7 are considered strong, correlations between .3 and .7 are moderate, and correlations less than .3 are weak. With that said, the results indicate that not only is this relationship positive but the relationship between selfefficacy and self-esteem is also moderately strong, $r=.63$ (Cronk, 2012). This finding can be best understood to mean that when an individual's self-esteem increases, so will an individual's levels of self-efficacy. For example, as one begins to think of oneself in 


\section{SELF-DISCLOSURE AND SELF-EFFICACY IN ONLINE DATING}

more of a positive way (self-esteem), then how one believes one will perform at

executing a task will rise as well (self-efficacy).

When addressing RQ2a, the researcher conducted a correlation test to identify the relationship between self-disclosure and self-efficacy. Specifically, the researcher conducted this analysis with each subscale of self-disclosure (honesty, amount, conscious intent, and positive valence) and the self-efficacy variable. After conducting this analysis, the researcher found that self-efficacy does not have any significant relationship with any of the self-disclosure subscales: honesty, $r(111)=.18, p=.06$, amount, $r(111)=.03, p$ $=.72$, conscious intent, $r(111)=.12, p=.21$, or positive valence, $r(111)=-.03, p=.74$. For RQ2b, the researcher also sought to examine the gender differences in selfdisclosure and self-efficacy. To accomplish this, the researcher split the data file by gender and compared the statistical significance for men and women and their relationship with the self-disclosure subscales and self-efficacy. Upon completion of the data analysis of the female participants, the researcher found that, among the female participants, there was not a statistically significant correlation between self-efficacy and the self-disclosure subscales: honesty, $r(111)=.22, p=.15$, amount, $r(111)=.16, p=.92$, 


\section{SELF-DISCLOSURE AND SELF-EFFICACY IN ONLINE DATING}

valence, $r(111)=-.24, p=.11$, or conscious intent, $r(111)=-.46, p=.76$.

When the researcher conducted this data analysis on the male participants, the researcher found that there was a statistically significant positive correlation among male participants and the correlation between conscious intent and self-efficacy, $r(111)=.29$, $p<.01$. The researcher identified this positive correlation to be weak, $r=.29$ (Cronk, 2012). If conscious intent can be interpreted as strategic motivations or strategic success behind self-disclosure, then the result from this data analysis can be most easily understood to mean that a male individual with greater conscious intent will think more highly of himself when he completes a task. For example, if a male individual was wanting to find a romantic partner online, his conscious intent (strategy) behind disclosing information may lead to better perceived success of finding a partner; in turn, his levels of self-efficacy will rise because he feels he can accomplish this with greater success with each partner he finds.

The results in the rest of the data analysis were not statistically significant for the male participants: honesty, $r(111)=.16, p=19$, amount, $r(111)=.07, p=.60$, or valence, $r(111)=.10, p=.44$. 


\section{SELF-DISCLOSURE AND SELF-EFFICACY IN ONLINE DATING}

Additionally, the researcher conducted an independent $t$-test that examined the

differences in self-disclosure based on gender. After conducting the data analysis, the researcher found that there was not a statistical significance between means regarding honesty, $t(110)=.77, p=.19$. For honesty, the mean for men $(M=3.40, S D=.84)$ was not significantly different than that for women $(M=3.54, S D=.95)$. The researcher also found there was not a statistical difference regarding amount of self-disclosure, $t(110)$ $=.94, p=.36)$. The mean for men $(M=2.85, S D=.72)$ was not significantly different than that for women $(M=2.98, S D=.79)$. Additionally, in regards to valence, the gender difference between men $(M=3.67, S D=.71)$ and women $(M=3.56, S D=.61)$ was not of any significance, $t(110)=-.82, p=.42$. During the data analysis, the researcher did find that there was a statistical difference in the conscious intent, $t(110)=-.87, p<.05$. The men $(M=3.87, S D=.63)$ did demonstrate that they have higher levels of conscious intent when self-disclosing information compared to women $(M=3.74, S D=.84)$. With this said, Hypothesis 1 was supported in the present study with the researcher identifying that there were gender differences in self-disclosure within online romantic relationships. Although the researcher found this support in only one subscale of self-disclosure, there 


\section{SELF-DISCLOSURE AND SELF-EFFICACY IN ONLINE DATING}

were still identifiable gender differences. This result can be understood to mean that men have more strategic success or strategic motivations behind their self-disclosing of information than women have.

For Hypothesis 2, self-esteem is positively correlated with self-disclosure within romantic relationships online. The researcher conducted a correlation test with selfesteem and the components of self-disclosure that were examined in the study: honesty, amount, positive valence, and conscious intent. The researcher found that in regards to self-esteem being correlated with honesty, this relationship was not significant, $r(111)$ $=.12, p=.20$. The researcher also found that there was not a significant relationship with amount, $r(111)=-.76, p=.42$, or intent, $r(111)=.01, p=.93$. However, the researcher did find that self-esteem does share a statistically significant positive relationship with valence, $r(111)=.20, p<.05$. This positive relationship is weak, $r=.20$. Self-esteem refers to thinking about oneself in a positive or negative way, and valence refers to the extent to which the information one discloses about oneself is positive or negative; conceptually, one can see that these two variables could be related. An example of how this result can be translated is if an individual has low self-esteem, then the information 


\section{SELF-DISCLOSURE AND SELF-EFFICACY IN ONLINE DATING}

disclosed about the individual will also be negative (valence).

In summary, the present study has generated various results that all contribute to

what we currently know about online dating and how these variables relate to one another.

From this study, the researcher was able to conclude from RQ1 that there is a positive correlation between self-efficacy and self-esteem that is moderately strong. The researcher concluded from RQ2a that self-efficacy does not have a significant relationship with any of the self-disclosure subscales utilized in this study. In RQ2b, there was not a significant correlation between self-disclosure and self-efficacy among female participants, but there was a statistically significant relationship among male participants. Among men, there was a weak, but statistically significant, relationship between selfdisclosure and self-efficacy. Specifically, this correlation was regarding conscious intent.

In addition, Hypothesis 1 was supported when the present study identified a gender difference in self-disclosure, specifically in conscious intent. Finally, Hypothesis 2 was supported when the researcher identified that self-esteem is positively correlated with self-disclosure. This weak correlation was specific to conscious intent. The next chapter provides a discussion of the impact the findings have on communication, online 


\section{SELF-DISCLOSURE AND SELF-EFFICACY IN ONLINE DATING}

daters, their relationships, and interpersonal communication, and provides a discussion of the relationship the findings have to previous studies. 


\section{SELF-DISCLOSURE AND SELF-EFFICACY IN ONLINE DATING}

\section{Chapter 5: Discussion}

The underlying purpose of this study was to contribute to the current body of

literature that is available on interpersonal communication in the context of online dating and to provide insight into a gap in the literature with prominent variables. Interesting results have been discovered that further our current knowledge about online dating and the ways in which self-disclosure and self-efficacy relate to one another in this environment. The study suggests a possible new way these variables can be researched. This chapter interprets the results for the three research questions and two hypotheses tested in this study.

From the results of the first research question —-whether there is a positive correlation between an individual's levels of self-efficacy and self-esteem-the researcher determined there is evidence of a significant correlation between self-efficacy and self-esteem, $r(111)=.63, p<.01$. To translate these results to an example, if an individual's self-efficacy level in online dating increases due to engaging in an online romantic relationship, then, according to the results from the present study, his or her self-esteem levels will rise as well. Conversely, if his or her online dating self-efficacy 


\section{SELF-DISCLOSURE AND SELF-EFFICACY IN ONLINE DATING}

level (finding a romantic partner online) decreases, his or her level of self-esteem will decrease as well. This finding parallels the reviewed literature of Bandura (year) regarding self-efficacy: Individuals with low self-efficacy levels have low aspirations and a weak commitment to completing any goals they set (Bandura, 1994). With low aspirations and a weak commitment to finding a romantic partner, the level of self-esteem an individual has will decrease. This result of the statistically significant relationship between self-efficacy and self-esteem was supported by the literature, as it helped demonstrate and solidify our current understanding of self-efficacy and self-esteem. In essence, as Bandura's seminal work showed and this study supports, low self-efficacy levels contribute to low levels of self-esteem. The literature demonstrated the behavior associated with low self-efficacy levels. This behavior is then translated to self-esteem levels, as it demonstrates the correlation found in the research study.

The scenario outlined above illuminates the correlation between these variables and provides a clearer understanding of how this result has an impact on our current knowledge base about self-efficacy and self-esteem. Through understanding this correlation, one can gain insight into why online daters feel the way they feel regarding 


\section{SELF-DISCLOSURE AND SELF-EFFICACY IN ONLINE DATING}

self-esteem and self-efficacy online. Additionally, the result also has the potential to impact not only online daters but also how individuals may understand one another online because it provides knowledge of the relationship between self-efficacy and selfesteem. As mentioned previously, this insight on how these variables interrelate allows online daters to understand how online daters may behave.

With this refocused understanding of how self-esteem and self-efficacy play a role in online dating and how one may feel about oneself, the researcher investigated selfefficacy further to identify if there is a relationship with self-disclosure (RQ2a). The literature suggested that there was a relationship between self-disclosure and self-esteem and a relationship between self-esteem and self-efficacy but no relationship between selfefficacy and self-disclosure. This gap in the literature provided the basis of the thought process for the possible relationship between the two variables, as examined in the present study. Additionally, Sprecher and Hendrick (2004) explained that self-disclosure is in need of further study. With this in mind, RQ2a was designed to address a possible gap in the literature.

As mentioned in the results, there was not a statistically significant relationship 


\section{SELF-DISCLOSURE AND SELF-EFFICACY IN ONLINE DATING}

between the self-disclosure subscales and self-efficacy within online dating among this sample, honesty, $r(111)=.18, p=.06$, for amount, $r(111)=.03, p=.72$, for conscious intent, $r(111)=.12, p=.21$, or for positive valence, $r(111)=-.03, p=.74$. This result was unexpected because the literature demonstrated a possible relationship between these two variables. The literature review outlined how the variables are related to one another, but there was not any literature bridging the gap between self-disclosure and self-efficacy with online dating.

Although the results from RQ2a did not reveal a new relationship between selfdisclosure and self-efficacy, it did contribute to the literature about interpersonal communication by providing evidence that these two variables do not appear to share a direct relationship. This contribution allows future researchers and individuals to understand that, in this study, a statistically significant relationship did not exist.

It may be that the scales used in this study contributed to the finding that there was not a statistically significant relationship between self-disclosure and self-efficacy. As mentioned earlier, after doing a through review of the literature, the researcher identified no research that looked specifically at self-disclosure and self-efficacy. With 


\section{SELF-DISCLOSURE AND SELF-EFFICACY IN ONLINE DATING}

this in mind, it's possible that a scale needs to be developed specifically to analyze this relationship in the online dating environment. The scales utilized in this study may not have been sensitive enough to detect a potential relationship.

Despite the absence of a statistically significant relationship between selfdisclosure and self-efficacy, the follow-up research question (RQ2b) examined whether gender differences were present in the relationship between self-disclosure and selfefficacy in an online dating environment. Data analysis points to a statistically significant relationship between conscious intent and self-efficacy among men as compared to women, $r(111)=.29, p<.01$. The researcher identified this positive correlation to be weak, $r=.29$ (Cronk, 2012).

This result paralleled a result found in a study conducted by Yuan (2002) and a study by Chiou (2006). The finding from Yuan's study indicated that women, in comparison to men, were more sensitive about disclosing information regarding their sexuality. Chiou found that men self-disclose about sexual topics more liberally than women do. Yuan provided a possible explanation that Taiwanese women felt that cybersex was unsafe and unreal in regard to the use of sex chat rooms. This explanation 


\section{SELF-DISCLOSURE AND SELF-EFFICACY IN ONLINE DATING}

could possibly translate to the present study in regards to conscious intent and self-

efficacy. The finding that men have higher levels of conscious intent than women do could be due to the fact that women may find computer-mediated communication less real and possibly less safe than men find it to be. If that is the case, it would provide one possible reason why men have higher levels of conscious intent compared to women.

The researcher is aware of the positive relationship between self-esteem and selfefficacy, but now the researcher is also aware that conscious intent (self-disclosure) is also connected to men's level of self-efficacy. A real-world example of the findings thus far could consist of a man participating in online dating who possesses a high level of self-esteem. Since this man has a high level of self-esteem, his self-efficacy level will rise. With this rise in self-efficacy level, the male online dater will have a higher level of conscious intent (deliberateness) behind any information disclosed.

In taking a step back, one criticism social penetration theory (Altman \& Taylor, 1973) has faced over the years is that it treats all self-disclosure as the same, whether the self-disclosure is on the part of a man or a woman. When this theory was originally created, gender was not taken into consideration. Since then, there have been numerous 


\section{SELF-DISCLOSURE AND SELF-EFFICACY IN ONLINE DATING}

articles regarding self-disclosure and gender, but this study exemplifies how the original theory has a couple of opportunities, specifically with gender differences and self-

disclosure. This study identified that men have higher levels of conscious intent; therefore the results raise the question of how conscious intent (e.g. purposefulness, motivation, deliberateness) impacts the social penetration theory when applied to online and offline contexts. This is an interesting concept to think about because the main idea behind the social penetration theory is that intimacy grows as interaction between individuals progresses from the outer layers to the inner layers of getting to know someone, from less intimate to more intimate (Wood, 2010). With this in mind, the conscious intent men seem to employ online may result in a more expedited disclosure than in computer-mediated communication among women. Although the social penetration theory provides a great framework for understanding relationships and selfdisclosure, it was created during a time when social networks and online dating did not exist. In turn, the social penetration theory often struggles to explain the new online communication styles that have developed.

To support this example further, this research study did support Hypothesis 1 by 


\section{SELF-DISCLOSURE AND SELF-EFFICACY IN ONLINE DATING}

confirming that there is a significant statistical difference between genders regarding self-

disclosure, specifically regarding conscious intent. The present study's result could also provide insight into one of the findings from Boneva, Kraut, and Frohlich's (2001) study.

In their study (2001), as outlined in the literature review, the researchers found that women indicated e-mail use to be more gratifying than men found it to be.

Additionally, women were found to be more likely to use e-mail to keep in touch with friends and family who live far away. With this in mind, men who have higher conscious intent would be more inclined to use e-mail for a purpose, not just for maintaining relationships. This insight into how men and women interact with computer-mediated communication could be translated into the context of social networks and dating Web sites. Women who find an individual online may be more than willing to initiate a friendship or romantic relationship, but men participating in similar online social networks or dating Web sites may disclose information for the specific purpose of finding a romantic partner. This would be representative of the present study's results and how this result could contribute to the communication literature and to the understanding of increased levels of conscious intent in men. 


\section{SELF-DISCLOSURE AND SELF-EFFICACY IN ONLINE DATING}

In reference to Hypothesis 2, the researcher did find that the there was a weak positive relationship between self-esteem and self-disclosure, specifically valence, $r(111)$ $=.20, p<.05$. This can be best understood to mean that when an individual discloses positive information regarding her- or himself, her or his level of self-esteem rises. For example, if a male online dater discloses information about himself in a positive light, his level of self-efficacy will rise, and, in turn, the level of conscious intent behind his disclosure of information will continue to be more intentional as he tries to satisfy his goal of finding a romantic partner online.

This study contained results that paralleled a study conducted by MacGregor and Holmes (2011). They found that in written and verbal communication in a romantic relationship, people were less positive in their disclosures when they believed that that the recipient possessed low self-esteem. In turn, people in close relationships who exhibited these behaviors often experienced relationship problems.

This result from the present study is supported by the existing literature and contributes to the literature surrounding interpersonal communication in that it possibly alludes to future research opportunities to gain further understanding of gender and self- 


\section{SELF-DISCLOSURE AND SELF-EFFICACY IN ONLINE DATING}

disclosure in online dating.

By conducting a research study to fill in the gap in the literature surrounding online dating and interpersonal communication while providing critical insight into how self-disclosure for men is connected to other variables, researchers could gain more thorough insight into how self-disclosure is impacted by outlying variables that have not yet been researched. Furthermore, this study has provided insight into how self-efficacy and self-esteem are correlated with each other in an online dating relationship.

This study was also able to contribute to the current body of literature by demonstrating that gender influences the relationship between self-efficacy and self-

disclosure. With the various results from the study, avenues have opened to future research that can further our knowledge about online dating as it continues to grow into a more common way of engaging in romantic relationships.

\section{Future Research}

Although the present study accomplished its objectives and provided an answer to the question regarding the relationship between self-disclosure and self-efficacy, it also provided evidence and a possible path to pursue with future research on how the variables 


\section{SELF-DISCLOSURE AND SELF-EFFICACY IN ONLINE DATING}

may interrelate in an online dating environment.

For future research, it would be beneficial to continue to explore how the

variables in the present study interrelate. Prior to the present study, self-disclosure, selfesteem, and self-efficacy had not been studied in this environment together and as a conceptual set. As the results were translated in the discussion section, it is possible to identify a possible process of how different variables interrelate. The process that was identified in this study could be an area for future research. As such, it would provide an understanding of how these variables are related in a different fashion or even how other variables interrelate in this process as well.

Additionally, because there were gender differences in the correlations to the subscales of self-disclosure, future research regarding gender and self-disclosure may be beneficial to gaining a full understanding of how men and women operate in online dating.

It also may be beneficial to conduct a similar study with a longitudinal design.

Although the self-disclosure scale measures patterns of self-disclosure, being able to identify an individual's pattern of self-disclosure over time may yield interesting results 


\section{SELF-DISCLOSURE AND SELF-EFFICACY IN ONLINE DATING}

that have not been discovered.

Furthermore, understanding the role online profiles play in self-disclosure could provide critical insight into online dating, as the majority of the Web sites require the creation of profiles. With the profiles, self-disclosure will take place visually through images and in written form. By examining self-disclosure in those avenues, we can understand the correlations between self-efficacy, self-esteem, and self-disclosure and further our knowledge in the online dating and communication literature.

In regard to the New General Self-Efficacy scale (Chen, Gully, \& Eden, 2001), the way it is written is with a positive bias. In turn, this may result in inflated or deflated mean scores, which could ultimately impact the results. For future research, it would be beneficial to use a scale that did not contain positive bias so the results would not have a chance of being skewed.

\section{Limitations}

One limitation of this study is the manner in which the sample was gathered.

Although the participants had the ability to indicate the extent of their involvement with online dating, perhaps future research could gather a sample specifically from online 


\section{SELF-DISCLOSURE AND SELF-EFFICACY IN ONLINE DATING}

dating Web sites. This will ensure that all participants have participated in online dating and will allow for more generalizable results that are more representative of the online dating community.

In addition to changing how the sample is gathered, it would be beneficial to also incorporate a larger sample size to accomplish this type of study. A larger sample will ensure the results are more representative of the online dating community. With both of these limitations addressed, the results from a similar study could provide deeper insight into online dating.

After the results were analyzed, it was discovered that the participants had completed the survey in an average time of 5 minutes and 8 seconds. This is different from the amount of time it took to complete the survey when it was pilot-tested, which was an average of 10-15 minutes, as indicated on the survey. With this shortened time for completing the survey, it is possible that the participants did not fully understand some questions or that they hastily filled out the survey. For future research, it would be beneficial to have more thorough directions to remind the participants that they should not rush when taking the survey. 


\section{SELF-DISCLOSURE AND SELF-EFFICACY IN ONLINE DATING}

\section{Conclusion}

In conclusion of this research study, the researcher can determine that there were several findings that further enhance our understanding regarding interpersonal communication and what we currently know. The possibility of identifying a process of how these variables interrelate in an online dating environment is a great starting point for future research, and it also demonstrates that this research study accomplished its goal of adding to the current body of literature regarding online dating and interpersonal communication.

This study has provided evidence from existing literature to demonstrate the ways in which these variables have already been studied, but this study also encourages researchers to continue being aggressive in the pursuit of knowledge, as there are still plenty of research opportunities available, including the ones outlined in this study. 


\section{SELF-DISCLOSURE AND SELF-EFFICACY IN ONLINE DATING}

\section{References}

Altman, I., \& Taylor, D. (1973). Social Penetration: The Development of Interpersonal Relationships. New York: Holt, Rinehart and Winston.

Anderson, T., \& Emmers-Sommer, T. (2006). Predictors of Relationship Satisfaction in Online Romantic Relationships. Communication Studies, 37(2), 153-172.

Arslan, C., Hamarta, E., \& Uslu, M. (2010). The Relationship between Conflict Communication, Self-Esteem and Life Satisfaction in University Students. Educational Research and Reviews, 5(1), 31-34.

Babbie, E. R. (2007). The practice of social research (11th ed.). Belmont, CA: Thomson Wadsworth.

Bandura, A. (1994). Self-efficacy. In V. S. Ramachaudran (Ed.), Encyclopedia of human behavior (Vol. 4, pp. 71-81). New York: Academic Press. (Reprinted in H. Friedman [Ed.], Encyclopedia of mental health. San Diego: Academic Press, 1998).

Bandura, A. (1997). Self-efficacy: the exercise of control. New York: W.H. Freeman.

Bargh, J.A. and K.Y.A. McKenna (2004) The Internet and Social Life. Annual Review of Psychology, 55, 573-90.

Betz, N., \& Klein, K. (1996). Relationships Among Measures of Career Self-Efficacy, Generalized Self-Efficacy, and Global Self-Esteem. Journal of Career Assessment, $4(3), 285-298$.

Blascovich, J., \& Tomaka, J. (1993). Measures of Self-Esteem. In J.P. Robinson, P.R. 


\section{SELF-DISCLOSURE AND SELF-EFFICACY IN ONLINE DATING}

Shaver, and L.S. Wrightsman (Eds.), Measures of Personality and Social

Psychological Attitudes, (3 ${ }^{\text {rd }}$ ed.; pp. 115-160). Ann Arbor: Institute for Social Research.

Blue, L. (2010, August 17). How couples meet. Healthland: TIME.com. Retrieved February 8, 2012, from http://healthland.time.com/2010/08/17/how-couples-meet/

Boneva, B., Kraut, R., \& Frohlich, D. (2001). Using E-mail for Personal Relationships: The Difference Gender Makes. American Behavioral Scientist, 45, 530-549.

Briggle, A. (2008). Real friends: how the Internet can foster friendship. Ethics and Information Technology, 10, 71-79.

Burt, I., Lewis, S., Beverly, M., \& Patel, S. (2010). Does High Educational Attainment Limit the Availability of Romantic Partners? The Family Journal, 18(4), 448-454.

Byers, E. S., \& Demmons, S. (1999). Sexual Satisfaction and Sexual Self-Disclosure Within Dating Relationships. The Journal of Sex Research, 36, 180-189.

Chiou, W. (2006). Adolescents' Sexual Self-Disclosure on the Internet: Deindividuation and Impression Management. Adolescence, 41(163), 547-561.

Cooper, A. and L. Sportolari (1997). Romance in Cyberspace: Understanding Online Attraction. Journal of Sex Education and Therapy 22(1): 7-14.

Cornwell, B., \& Lundgren, D. (2001). Love on the Internet: involvement and misrepresentation in romantic relationships in cyberspace vs. real space. Computers in Human Behavior, 17, 197-211.

Cronk, B. C. (2012). How to use spss: a step-by-step guide to analysis and interpretation. 


\section{SELF-DISCLOSURE AND SELF-EFFICACY IN ONLINE DATING}

\section{S.1.: Pyrczak Publishing.}

Cocking, D., \& Matthews, S. (2001) Unreal Friends. Ethics and Information Technology, 2(4): $223-231$.

Derlega, V. J., \& Berg, J. H. (1987). Self-disclosure: theory, research, and therapy. New York: Plenum Press.

Duck, S., \& McMahan, D. T. (2009). The basics of communication: a relational perspective. Thousand Oaks, Calif.: Sage.

eHarmony. (n.d.). eHarmony \#1 Trusted Singles Online Dating Site-More than Personals. Retrieved April 29, 2012, from http:/www.eharmony.com/

Ellin, A. (2009, February 11). The Romance of Recession - Dating Is on the Rise NYTimes.com. The New York Times. Retrieved January 27, 2011, from http://www.nytimes.com/2009/02

Finding true love: A look at the history of dating - TODAY.com. (2005, Feb. 17) TODAY.com. Retrieved 13 May 2012. http://today.msnbc.msn.com/id/6967668/ns/today/t/finding-true-love-lookhistory-dating/\#.T7AWyFEj5rh

Frost, J., Chance, Z., Norton, M., \& Ariely, D. (2008). People are Experience Goods: Improving Online Dating with Virtual Dates. Journal of Interactive Marketing, $22(1), 51-61$.

Gibbs, J., Ellison, N., \& Heino, R. (2006). Self-Presentation in Online Personals : The Role of Anticipated Future Interaction, Self-Disclosure, and Perceived Success in 


\section{SELF-DISCLOSURE AND SELF-EFFICACY IN ONLINE DATING}

Internet Dating. Communication Research, 33, 152-177.

Gibbs, J., Lai, C., \& Ellison, N. (2009). First Comes Love, Then Comes Google: An Investigation of Communication Privacy Management Strategies and SelfDisclosure in Online Dating. International Communication Association, 1, 1-46.

Greene, K., Derlega, V. L., \& Mathews, A. (2006). Self-disclosure in personal relationships. In A. Vangelisti \& D. Perlman (Eds.), Cambridge handbook of personal relationships (pp. 1268-1328). Cambridge, UK: Cambridge University Press.

Griffin. E. \& Sparks. G. (1990). Friends forever: A longitudinal exploration of intimacy in same-sex friends and platonic pairs. Journal of Social and Personal Relationships, 7, 29-46.

Hardey, M. (2004). Mediated Relationships: Authenticity and the possibility of romance. Information, Communication \& Society, 7(2), 207-222.

How Many People Use Online Dating Services?. (n.d.). Online Dating Newsletter. Retrieved September 18, 2011, from http://www.onlinedatingnewsletter.com/datingadvice/345/how-many-people-useonline-dating-services.html

Jourard, S. M. (1964). The Transparent Self. New York: Van Nostrand.

Junge, M., \& Dretzke, B. (1995). Mathematical Self-Efficacy Gender Differences In Gifted/Talented Adolescents. Gifted child quarterly, 39(1), 22-26.

Levine, D. (2000). Virtual Attraction: What Rocks Your Boat. Cyberpsychology and 


\section{SELF-DISCLOSURE AND SELF-EFFICACY IN ONLINE DATING}

Behavior, 3(4), 565-73.

Lawson, H., \& Leck, K. (2006). Dynamics of Internet Dating. Social Science Computer Review, 24(2), 189-208.

Lo, S. (2008). The Nonverbal Communication Functions of Emoticons in ComputerMediated Communication. CyberPyschology \& Behavior, 11(5), 595-597.

MacGregor, J., \& Holmes, J. (2011). Rain on My Parade: Perceiving Low Self-Esteem in Close Others Hinders Positive Self-Disclosure. Social psychological and personality science, 2(5), 523-530.

Margolis, H., \& McCabe, P. (2006). Improving Self-Efficacy and Motivation: What to do, what to say. Intervention in School and Clinic, 41(4), 218-227.

Match.com. (n.d.). Match.com ${ }^{\circledR}$ : The Leading Online Dating Site for Singles \& Personals. Retrieved February 8, 2012, from http://www.match.com/index.aspx

McCown, J., Fischer, D., Page, R., \& Homant, M. (2001). Internet Relationships: People Who Meet People. Cyber Psychology \& Behavior, 4(5), 593-596.

McKenna, K., Green, A., \& Gleason, M. (2002). Relationship Formation on the Internet: What's the Big Attraction?. Journal of Social Issues, 58(1), 2002.

McKenna, K. Y. A., \& Bargh, J. A. (2000). Plan 9 from Cyberspace: the Implications of the Internet for Personality and Social Psychology. Personality and Social Psychology Review 4(1): 57-75.

Merkle, E., \& Richardson, R. (2000). Digital Dating and Virtual Relating: Conceptualizing Computer Mediated Romantic Relationships. Family Relations, 


\section{SELF-DISCLOSURE AND SELF-EFFICACY IN ONLINE DATING}

49(2), 2000.

Mesch, G., \& Beker, G. (2010). Are Norms of Disclosure of Online and Offline Personal Information Associated with the Disclosure of Personal Information Online? Human Communication Research, 36, 570-592.

Mruk, C. J. (2006). Self-esteem research, theory, and practice toward a positive psychology of self-esteem (3rd ed.). New York: Springer Pub.

Online Daters More Confident Than Offline Daters. (2004, March 12). Online Dating Magazine - Dating Services, Tips, Advice, and News. Retrieved April 18, 2011, from http://www.onlinedatingmagazine.

Online Dating Statistics: How to Succeed With Online Dating? (2009, February 23). Dating. Retrieved June 29, 2011, from www.articlealley.com/online-datingstatistics-how-to-succeed-with-online-dating-794505.html

Pajeras, F. (n.d.). Current Directions in Self-Efficacy Research. Current Directions in Self-efficacy Research. Retrieved May 22, 2011, from http://www.des.emory.edu/mfp

Pajares, F., \& Schunk, D. (n.d.). Self-efficacy. College - Educational Studies Home . Retrieved February 23, 2012, from http://des.emory.edu/mfp/PajaresSchunk20 Pauley, P., and Emmers-Sommer, T. (2007). The Impact of Internet Technologies on Primary and Secondary Romantic Relationship Development, Communication Studies, 58(4), 411-427.

Peter, J., \& Valkenburg, P. (2007). Who looks for casual dates on the Internet? A test of 


\section{SELF-DISCLOSURE AND SELF-EFFICACY IN ONLINE DATING}

the compensation and the recreation hypotheses. New Media Society, 9(3), 455474.

Rodebaugh, T. (2005). Self-efficacy and social behavior. Behavior Research and Therapy, 2006, 1831-1838.

Rosen, L., Cheever, N., Cummings, C., \& Felt, J. (2008). The impact of emotionality and self-disclosure on online dating versus traditional dating. Computers in Human Behavior, 24, 2124-2157.

Rosenberg, Morris. (1989). Society and the Adolescent Self-Image. Revised edition. Middletown, CT: Wesleyan University Press

Rosenberg, Morris. (1986). Conceiving the Self. Malabar, FL: Krieger.

Rosenfeld, M. J., (2010, August 14) Meeting Online: The Rise of the Internet as a Social Intermediary. Paper presented at the annual meeting of the American Sociological Association Annual Meeting, Hilton Atlanta and Atlanta Marriott Marquis, Atlanta, GA Online. Retrieved November 29, 2011 from http://www.allacademic.com/meta/p409508_index.html

Rumbough, T. (2001). The Development and Maintenance of Interpersonal Relationships Through Computer-Mediated Communication. Communication Reports Research, $1,223-229$.

Sciangula, A., \& Morry, M. (2009). Self-Esteem and Perceived Regard: How I See Myself Affects My Relationship Satisfaction. The Journal of Social Psychology, 149(2), 143-158. 


\section{SELF-DISCLOSURE AND SELF-EFFICACY IN ONLINE DATING}

Sherer, M., Maddux, J. E., Mercandante, B., Prentice-Dunn, S., Jacobs, B., \& Rogers, R. W. (1982). The Self-Efficacy Scale: Construction and validation. Psychological Reports, 51, 663-671.

Sparrevohn, R., \& Rapee, R. (2009). Self-disclosure, emotional expression and intimacy within romantic relationships of people with social phobia. Behavior Research and Therapy, 47, 1074-1078.

Sprecher, S., \& Hendrick, S. (2004). Self-Disclosure in Intimate Relationships: Associations With Individual and Relationship Characteristics Over Time. Journal of Science and Clinical Pyschology, 6, 857-877.

Thurlow, C., Lengel, L. B., \& Tomic, A. (2005). Computer mediated communication: social interaction and the Internet (Repr. ed.). Thousand Oaks, CA: Sage Publications.

Tidwell, L., \& Walther, J. (2002). Computer-Mediated Communication Effects on Disclosure, Impressions, and Interpersonal Evaluations Getting to Know One Another a Bit at a Time. Human Communication Research, 28(3), 317-348.

Toma, C., Hancock, J., \& Ellison, N. (2008). Separating Fact From Fiction: An Examination of Deceptive Self-Presentation in Online Dating Profiles. Personality and Social Psychology Bulletin, 34(8), 1023-1036.

Usher, E. (2009). Sources of Middle School Students' Self-Efficacy in Mathematics: A Qualitative Investigation. American Educational Research, 46(1), 275-314.

Walther, J.B. (1996). Computer-mediated Communication. Impersonal, Interpersonal and 


\section{SELF-DISCLOSURE AND SELF-EFFICACY IN ONLINE DATING}

Hyperpersonal Interaction. Communication Research, 23(1), 3-43.

Walther, J.B., \& Parks, M.R. (2002). Cues Filtered Out, Cues Filtered in. Computermediated Communication and Relationships. In M.L. Knapp and J.A. Daly (Eds.), Handbook of Interpersonal Communication, (pp. 529-5 63).Thousand Oaks, CA: Sage.

Wheeless, L. R. (1978). A follow-up study of the relationships among trust, disclosure, and interpersonal solidarity. Human Communication Research, 4, 143-157.

Wheeless, L. R., \& Grotz, J. (1976). Conceptualization and measurement of reported selfdisclosure. Human Communication Research, 2, 338-346

Whitty, M., \& Mclaughlin, D. (2007). Online recreation: The relationship between loneliness, Internet self-efficacy and the use of the Internet for entertainment purposes. Science Direct, 23, 1433-1446.

Wong, W., \& Newspapers, T. (2012, July 22). Online dating grows, sheds stigma Chicago Tribune. Featured Articles From The Chicago Tribune. Retrieved February 22, 2012, from http://articles.chicagotribune.com/2010-0722/business/sc-biz-0723-online-dating--20100722_1_dating-online-meeting

Wood, J. T. (2010). Interpersonal communication: everyday encounters (6th ed.). Boston, MA: Wadsworth, Cengage Learning.

Wright, K. (2004). On-line Relational Maintenance Strategies and Perceptions of Partners Within Exclusively Internet-based and Primarily Internet-based Relationships. Communication Studies, 55(2), 239-253. 


\section{SELF-DISCLOSURE AND SELF-EFFICACY IN ONLINE DATING}

Wysocki. D.K. (1996). Somewhere over the modem: Relationships over computer bulletin boards. (Unpublished doctoral dissertation.) University of CaliforniaSanta Barbara, Santa Barbara.

Wysocki. D.K. (1998). Let your fingers do the talking: Sex on an adult chat-time. Sexualities, I, 425-452.

Yuan, S. M. (2002). Emancipation or repression? A phenomenological study on the Taiwanese women's usage in the sex chat room. (Unpublished master's thesis.) National Nan Hwa University: Taiwan.

Zeigler-Hill, V., Fulton, J., \& McLemore, C. (2011). The role of unstable self-esteem in the appraisal of romantic relationships. Personality and Individual Differences, 51, $51-56$.

Zinkhan, G. (2004). Romance and the Internet: The E-Mergence of E-Dating. Advances in Consumer Research, 31, 153-58.

Zulkosky, K. (2009). Self-Efficacy: A Concept Analysis. Nursing Forum, 44(2), 93-102 


\section{SELF-DISCLOSURE AND SELF-EFFICACY IN ONLINE DATING}

\section{Appendix A: Informed Consent}

\section{Survey on Self-Disclosure and Self-Efficacy in Online Dating}

First, thank you so much for choosing to participate in my survey!

During this survey you will be asked a number of questions discussing how you disclose information about yourself to other individuals and questions pertaining to your selfperception. In addition, there will be questions regarding online dating and your Internet use. There are only very minimal risks associated with taking this survey, as you might feel uncomfortable answering some of the questions, but I would like to remind you that the answers collected from this survey are both ANONYMOUS and CONFIDENTIAL, meaning there will be no way to link you to the responses you provided.

In addition to being anonymous and confidential this survey is also voluntary, so you may choose to skip questions in which you feel uncomfortable answering. I would also ask that you only complete this survey if you are 18 years of age or older.

This survey should take approximately 10-15 minutes to complete. I ask that you answer the questions as honestly and carefully as possible remembering that there is no way to trace you to the responses you give.

If you have any questions about the study please contact the primary researcher, Andrew España, at aespana17@gmail.com

Thank you very much for your participation! 
SELF-DISCLOSURE AND SELF-EFFICACY IN ONLINE DATING

\section{Appendix B: Complete Survey}

\section{A. Please read the statement or question listed below and select the most accurate response in relation to you. The choices are Strongly Disagree, Disagree, Neutral, Agree, Strongly Agree.}

\section{New-General Self-Efficacy Scale}

1. I will be able to achieve most of the goals that I have set for myself.

2. When facing difficult tasks, I am certain that I will accomplish them.

3. In general, I think that I can obtain outcomes that are important to me.

4. I believe I can succeed at most any endeavor to which I set my mind.

5. I will be able to successfully overcome many challenges.

6. I am confident that I can perform effectively on many different tasks.

7. Compared to other people, I can do most tasks very well.

8. Even when things are tough, I can perform quite well.

\section{Self-Esteem Scale}

9. I feel that I'm a person of worth, at least on an equal plane with others.

10. I feel that I have a number of good qualities.

11. All in all, I am inclined to feel that I am a failure.

12. I am able to do things as well as most other people.

13. I feel I do not have much to be proud of.

14. I take a positive attitude toward myself

15. On the whole, I am satisfied with myself.

16. I wish I could have more respect for myself.

17. I certainly feel useless at times.

18. At times I think I am no good at all

General Self-Disclosiveness Scale

Honesty 


\section{SELF-DISCLOSURE AND SELF-EFFICACY IN ONLINE DATING}

19. I am always honest to those I meet online.

20. My statements about my feelings, emotions, and experiences to those I meet online are always accurate self-perceptions.

21. The things I revel about myself to those I meet online are always accurate reflections of who I really am.

22. I am not always honest in my self-disclosures with those I meet online.

23. I always feel completely sincere when I reveal my own feelings, emotions, behaviors, or experiences to those I meet online.

24. I do not always feel completely sincere when I reveal my own feelings, emotions, behaviors, or experiences to those I meet online.

Amount

25. I often discuss my feelings about myself with those I meet online.

26. My statements of my feelings are usually brief with those I meet online.

27. I usually communicate about myself for fairly long periods at a time with those I meet online.

28. I do not often communicate about myself with those I meet online.

29. I don't express my personal beliefs and opinions to those I meet online very often.

Positive Valence

30. I often disclose negative things about myself to those I meet online.

31. I usually disclose only positive things about myself with those I meet online.

32. On the whole, my disclosures about myself to those I meet online are more positive than negative.

Intent

33. When I express my personal feelings about myself to those I meet online, I consciously intend to do so

34. When I reveal my feelings about myself to those I meet online, I consciously intend to do so

\section{B. Please answer the following questions as accurately as possible by selecting one answer or typing a response in the text box.}

35. Please indicate your age: 


\section{SELF-DISCLOSURE AND SELF-EFFICACY IN ONLINE DATING}

36. Please indicate your sex:
o male
○ female
$\circ$ other

37. Please indicate the racial category with which you identify:
- African-American/Black
- American Indian/ Alaskan
- Asian/ Pacific Islander
- Caucasian
○ Hispanic or Latino/a
○ Indian
- Two or more races
O Other

38. Please indicate the highest level of education you have completed:

○ Less than a high school diploma

○ High school diploma

○ Some college

○ Bachelor's Degree

- Master's Degree or equivalent

- Doctoral Degree or equivalent

39. Please indicate your annual household income level:
- less than $\$ 10,000$
○ $\$ 10,000$ to $\$ 30,000$
○ $\$ 30,000$ to $\$ 50,000$
○ $\$ 50,000$ to $\$ 75,000$
○ $\$ 75,000$ to $\$ 150,000$
○ More than $\$ 150,000$

40. How many days per week do you use the internet?

41. How many hours per day do you spend using the internet? 


\section{SELF-DISCLOSURE AND SELF-EFFICACY IN ONLINE DATING}

42. How many days per week do you spend actively trying to find a romantic partner online?

43. How many hours per day do you actively participate in online dating activate? (flirting, online dating, searching for a partner, etc.)

44. What is your most visited website?

45. Have you ever had a romantic relationship that was initiated online?

$$
\begin{array}{ll}
\circ & \text { Yes } \\
\circ & \text { No }
\end{array}
$$

46. What was the longest romantic relationship you initiated and maintained through the internet?

47. If you have, how long have you been an active participant of an online dating website? (e.g. match.com, eHarmony.com)

$$
\begin{array}{ll}
\circ & \text { N/A } \\
\circ & 0-3 \text { months } \\
\circ & 4-6 \text { months } \\
\circ & 6-12 \text { months } \\
\circ & \text { over a year }
\end{array}
$$

Thank you very much for your time - I appreciate your input! 